\title{
QUALI-QUANTITATIVE ANALYSIS OF EIGHT ROSMARINUS OFFICINALIS ESSENTIAL OILS OF DIFFERENT ORIGIN. FIRST REPORT.
}

\author{
Miraldi E., Giachetti D., Mazzoni G., Biagi M. \\ Department of Environmental Biology, University of Siena
}

\begin{abstract}
Aim. It is well known that the pharmacological activity of essential oils depends on their major components, which may vary enormously. The aim of the present study was to determine the chemical composition of samples of essential oil of rosemary of different origins, in order to identify the main therapeutic constituents, according to European Pharmacopoeian (EP).

Material and Methods. Analytical GC/MS was carried out on a total of eight samples of essential oil of rosemary: seven samples were commercial products from producers located in different geographical areas; the last sample was prepared in our laboratory from fresh flowering terminal sprigs of rosemary collected in Siena's Province.

Results. The most representative constituents of the essential oils tested, were 1,8-cineole and camphor. Other components also occurred in significant quantities in some samples, for example and $\alpha$ - and $\beta$-pinene, limonene and caryophyllene, indicating clear phytochemical differences among samples.

Discussion. The high quantity of eucalyptol and camphor detected in the samples made them particularly suited for treating minor respiratory disorders. Eucalyptol is expectorant and liquefies bronchial secretions; camphor increases the interval between inspiration and expiration and increases the activity of the parasympathetic nervous system, facilitating respiration. On the other hand, the essential oils analyzed by us were not suitable for perfume production, because they contained little or no positive aromatic components.

Key words. Rosmarinus officinalis, essential oil, 1,8-cineole, camphor.
\end{abstract}

\section{INTRODUCTION}

Rosmarinus officinalis L. is a xeromorphic species that grows spontaneously on sand, cliffs and stony places near the sea in Europe, Africa and Asia (1). In Italy it is spontaneous along all coasts except the northern Adriatic (1). Italian production of essential oil of rosemary is supplemented with imports from Spain, Morocco, ex-Yugoslavia region and Tunisia (2).

The plant is of economic importance because of essential oils extracted by steam distillation from fresh leaves. The European Pharmacopeia (3) lists the following constituents of "Rosemary Oil": $\alpha$ - and $\beta$ pinene, camphor, 1,8-cineole, camphene, limonene and borneol.

Distillation of essential oil is mainly carried out in Spain, France, Tunisia, Morocco, ex-Yugoslavia, Dalmatia, Sardinia and Sicily. Spain produces the largest quantity of this essence, the quality of which may vary considerably (4).

Conventional medicine recognizes various therapeutic properties of rosemary oil, principally those of antispasmodic (5), antiseptic and antimicrobic $(5,6,7)$, especially in respiratory diseases (8) and also those of stomachic, stimulant, revulsive and hyperemizing agent $(4,9)$.

It is well known that the pharmacological activity of essential oils depends on their major components, which may vary enormously. The aim of the present study was to determine the chemical composition of eight samples of essential oil of rosemary of different origins, in order to identify the main therapeutic constituents, according to European Pharmacopoeian (EP).

\section{MATERIALS AND METHODS}

\section{Essential oils}

A total of eight samples of essential oil of rosemary were analysed: seven samples were commercial products from producers located in different geographical areas. The oils were labelled as being steam distilled from fresh flowering sprigs of R. officinalis as described in EP. The other sample was prepared in the same way by us from fresh flowering terminal sprigs of rosemary collected in the municipality of S. Quirico d'Orcia (Siena, Italy).

\section{Gas chromatography-mass spectrometry}

Analytical GC/MS was carried out on a Varian 3800 (Varian, Walnut Creek, CA) gas chromatograph interfaced with a Varian Saturn 2000 mass spectrometer. A Rtx-5MS (Restek Bellefonte, PA, USA) column (30 m x $0.25 \mathrm{~mm}, 0.25 \mu \mathrm{m}$ film thickness) was employed, with helium as carrier gas (flow rate $1.0 \mathrm{~mL} / \mathrm{min}$ ). Samples were injected using the split sampling technique, ratio $1: 10 ; 1.0 \mu \mathrm{l}$ of sample (diluted 1:10 in chloroform) was injected. Oven temperature was held at $60^{\circ} \mathrm{C}$ for $8 \mathrm{~min}$, then programmed at $3^{\circ} \mathrm{C} / \mathrm{min}$ to $180^{\circ} \mathrm{C}$, held there for $5 \mathrm{~min}$. The MS operating parameters were: electron ionization $70 \mathrm{eV}$; scan $\mathrm{m} / \mathrm{z}$ range 40-650. Identification of the constituents was carried out by comparing the retention times with those of reference compounds or by peak-matching library search using the NBS/NIST library and comparison of the MS data with those published in references works $(10,11)$.

Correspondence to:

Elisabetta Miraldi

Department of Environmental Biology, Section of Pharmaceutical Biology, University of Siena

Via T.Pendola 62, 53100 Siena, Italy. Phone: (+39) 0577233517 Fax (+39) 0577233526

e-mail: miraldi@unisi.it 


\section{Results}

The volatile compounds identified in the eight rosemary samples are shown in Table 1, together with their respective percentages, in order of elution from the column.

\begin{tabular}{|c|c|c|c|c|c|c|c|c|}
\hline Compound & \multicolumn{7}{|c|}{ percentage concentration (\%) } \\
\hline Sample no. & $\mathbf{1}$ & $\mathbf{2}$ & $\mathbf{3}$ & $\mathbf{4}$ & $\mathbf{5}$ & $\mathbf{6}$ & $\mathbf{7}$ & $\mathbf{8}$ \\
\hline$\alpha$-pinene & 13.88 & 8.91 & 18.81 & 13.78 & 12.18 & 20.47 & 7.14 & 4.55 \\
\hline camphene & 3.71 & 4.69 & 6.92 & 3.53 & 4.29 & 3.91 & 2.60 & 2.93 \\
\hline$\beta$-pinene & 9.05 & 6.94 & 5.72 & 9.11 & 7.05 & 3.25 & 5.32 & 6.62 \\
\hline myrcene & 1.78 & 1.15 & 1.58 & 1.79 & 0.61 & 0 & $\operatorname{tr}$ & 0.53 \\
\hline limonene & 3.55 & 2.32 & 3.50 & 3.38 & 1.18 & 0 & $\operatorname{tr}$ & tr \\
\hline 1,8 -cineole & 48.25 & 46.65 & 37.11 & 46.82 & 50.08 & 38.59 & 60.28 & 45.22 \\
\hline linalool & 0.27 & 1.55 & 1.26 & 0.37 & 0 & 0 & $\operatorname{tr}$ & 0.89 \\
\hline camphor & 6.89 & 14.87 & 8.80 & 12.39 & 17.12 & 27.72 & 10.80 & 15.90 \\
\hline borneol & $\operatorname{tr}$ & 4.29 & 1.58 & 0.78 & 0 & 0 & 0.05 & 1.86 \\
\hline bornyl acetate & 1.96 & 1.82 & 10.06 & 2.40 & 0.54 & 2.84 & 6.22 & 11.09 \\
\hline caryophyllene & 5.11 & 5.91 & 4.31 & 5.68 & 6.92 & 3.21 & 7.65 & 10.41 \\
\hline
\end{tabular}

\section{Discussion}

Under "Rosmarini aetheroleum", the EP (3) lists eleven principal components characteristic of rosemary-type essence obtained from plants grown in Morocco, Tunisia and Spain. To characterize the samples of the present study, we therefore indicate the components listed in the EP as well as a further component, identified as caryophyllene, which we found in all samples in quantities sufficient to be considered representative. The EP specifies that essence from Spain is low in 1,8cineole (1-2.2\%), but high in $\alpha$-pinene (18-26\%) and camphor (13-21\%), whereas essence from north Africa are much richer in 1,8-cineole (38-55\%), with quantities of borneol, camphor and $\alpha$-pinene around $10 \%$. This is the most widely available essential oil.

In the analyzed samples, the most representative components were 1,8-cineole and camphor. According to Lugli and co-workers (5), a good essential oil of rosemary should contain $20-50 \%$ eucalyptol. Our samples had contents of 1,8-cineole from $37.11 \%$ (sample 3 ) to $60.28 \%$ (sample 7), and were therefore similar to African essences. They were also particularly rich in camphor, with values ranging from $6.89 \%$ (sample 1) to $27.72 \%$ (sample 6). According to the EP, Spanish essences have a camphor content in the range 13-21\% in contrast with the lower content (5-15\%) of African essences. However, the negative note of camphor is partly "neutralized" (in the organoleptic sense) by the good quantity of compounds imparting positive notes, for example the pungent but pleasant borneol, the floral fragrance of linalool and the sweet taste of bornyl acetate (samples 6 and 8). Sample 3, labelled as "bornyl acetate chemotype" did indeed contain the highest percentage of this component, except for sample 8 distilled by us.

The results of analysis showed that the essential oils were of the 1,8-cineole chemotype. The high quantity of eucalyptol and camphor detected in the samples made them particularly suited for treating minor respiratory disorders. Eucalyptol is expectorant and liquefies bronchial secretions; camphor increases the interval between inspiration and expiration and increases the activity of the parasympathetic nervous system, facilitating respiration. Eucalyptol and camphor are both revulsive agents, useful for circulatory disorders and rheumatic pain.

A camphor chemotype is mentioned for the first time in a recent aromatherapy text (4). Its parameters are: camphor up to $20 \%$, 1,8-cineole $15 \%$, borneol $5 \%$. Essences of this type have mainly been distilled in southeast France and Spain. This composition has marked tonic effects on muscles and circulation.

Only samples 3, 7 and 8 had the parameters of the bornyl acetate chemotype, which must contain at least $5 \%$ of this component. Bornyl acetate has colagog, coleretic and hepatoregenerative properties, especially when associated with phenolic essences (such as thyme oil), and facilitates intestinal peristalsis. The bornyl acetate chemotype is indicated as a coleretic, colagog, regulator of intestinal flora and general stimulant. However, the essential oils analyzed by us were not suitable for perfume production because they contained little or no positive aromatic components.

More extensive studies are needed to define the chemical characteristics of the various types of essential oil of Rosmarinus officinalis. The present study shows the need for greater clarity in differentiating 1,8-cineole, bornyl acetate and camphor chemotypes, in order to establish the pharmacological differences between the various components so as to provide products tailored to the disorders to be treated.

\section{REFERENCES}

1. Pignatti S. Flora d' Italia. Bologna, Edagricole 1982.

2. Della Loggia R. Piante officinali per infusi e tisane. Milano, OEMF editore SpA 1993.

3. European Pharmacopoeia 7th edition. Strasbourg, Council of Europe 2010.

4. Raynaud J. Prescription et Conseil en Aromathèrapie. Paris, Editions Tec e Doc Lavoisier 2006.

5. Lugli A, Pescari M, Monti F, Ghelardini C, Galeotti N. Monografie ESCOP-Edizione Italiana. Pistrino di Citerna (PG), Planta Medica Edizioni 2006.

6. Chiereghin P. Farmacia verde. Bologna, Edagricole 2002.

7. Sacchetti G, Maietti S, Muzzoli M, Scaglianti M, Manfredini S, Radice M, Bruni R. Comparative evaluation of 11 essential oils of different origin as functional antioxidants, antiradicals and antimicrobials. Food Chemistry 2005; 91 : 621-632.

8. Gedney JJ, Glover TL, Fillingim RB. Sensory and affective pain discrimination after inhalation of essential oils. Psychosom Med 2004; 66 (4): 599-606.

9. Gachkar L, Yadegari D, Bagher Razaei M, Taghizadeh M, Alipoor Astaneh S, Rasooli I. Chemical and biological characteristics of Cuminum cyminum and Rosmarinus officinalis essential oils. Food Chemistry 2007; 102: 898-904.

10. Adams RP. Identification of essential oils by Ion Trap Mass Spectroscopy. San Diego (California), Accademic Press 1989.

11. Adams RP. Identification of essential oil components by gas chromatography/mass spectroscopy. Carol Stream (Illinois), Allured Publishing Corporation 1995. 